\title{
LncRNA CANT1 suppresses retinoblastoma progression by repellinghistone methyltransferase in PI3KY promoter
}

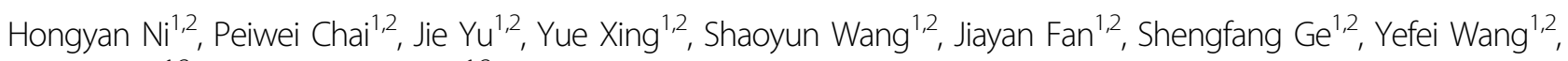
Renbing Jia ${ }^{1,2}$ and Xianqun Fan (10)

\begin{abstract}
Retinoblastoma (RB) is the most common malignant intraocular tumor of childhood. Recent studies have shown that long noncoding RNAs (IncRNAs), which are longer than $200 \mathrm{bp}$ and without protein-coding ability, are key regulators of tumorigenesis. However, the role of IncRNAs in retinoblastoma remains to be elucidated. In this study, we found that the expression of InCRNA CASC15-New-Transcript 1 (CANT1) was significantly downregulated in RB. Notably, overexpression of CANT1 significantly inhibited RB growth both in vitro and in vivo. Furthermore, IncRNA CANT1, which was mainly located in the nucleus, occupied the promoter of phosphoinositide 3-kinase gamma (PI3KY) and blocked histone methyltransferase hSET1 from binding to the PI3KY promoter, thus abolishing hSET1-mediated histone H3K4 trimethylation of the PI3KY promoter and inhibiting PI3KY expression. Furthermore, we found that silencing PI3KY either by IncRNA CANT1 overexpression or by PI3KY siRNA, reduced the activity of PI3K/Akt signaling and suppressed RB tumorigenesis. In summary, IncRNA CANT1 acts as a suppressor of RB progression by blocking gene-specific histone methyltransferase recruitment. These findings outline a new CANT1 modulation mechanism and provide an alternative option for the RB treatment.
\end{abstract}

\section{Introduction}

Long noncoding RNAs (lncRNAs) are transcripts longer than 200 bp with no apparent protein-coding ability, that are involved in numerous important biological phenomena such as $\mathrm{X}$ chromosome inactivation, chromosome conformation shaping, and DNA damage repair ${ }^{1-4}$. The functional roles and mechanism of action of some classically defined lncRNAs are well understood. For instance, lncRNA XIST coats the X chromosome, is expressed only from the inactive $\mathrm{X}$ chromosome $(\mathrm{Xi})$, and is essential for the silencing process ${ }^{2,5,6}$. LincRNA-ROR is an important

Correspondence: Yefei Wang (paper34@163.com) or

Renbing Jia (renbingjia@sjtu.edu.cn) or Xianqun Fan (fanxq@sjtu.edu.cn)

${ }^{1}$ Department of Ophthalmology, Ninth People's Hospital, Shanghai JiaoTong

University School of Medicine, Shanghai, China200011

${ }^{2}$ Shanghai Key Laboratory of Orbital Diseases and Ocular Oncology, Shanghai, China200011

These authors contributed equally: Hongyan Ni, Peiwei Chai, Jie Yu, Yue Xing Edited by E. Candi factor for the reprogramming process because its depletion or overexpression results in reduced or increased efficiency of reprogramming fibroblasts to iPSCs ${ }^{7}$. LncRNA non-coding RNA activated by DNA damage $(N O R A D)$ interacts with proteins involved in DNA replication and repair in steady-state cells and localizes to the nucleus upon replication stress or DNA damage stimulation $^{8,9}$. However, the functions of the majority of lncRNAs are unknown, and it is necessary to explore the functions of lncRNAs.

As IncRNAs play a key role in the maintenance of homeostasis, aberrant lncRNA expression may be an important trigger for a variety of diseases. LncRNA $B A C E 1-A S$ levels have been found to be increased along with amyloid $\beta$ levels across different regions in postmortem brains from Alzheimer's disease patients, and $B A C E 1-A S$ protects $B A C E 1$ mRNA from degradation ${ }^{10}$. LncRNA myocardial infarction associated transcript 
(MIAT) is notably elevated in angiotensin II (ANG-II)induced cardiac hypertrophy and forms a feedback loop with vascular endothelial growth factor and miR-150-5p to regulate endothelial cell function ${ }^{11,12}$. Therefore, aberrant lncRNA expression has attracted increasing attention in the study of the pathogenesis of the human disease.

Since many lncRNAs epigenetically regulate their targets, which are either tumor suppressors or oncogenes, the lncRNAs are closely associated with tumorigenesis. We previously reported that lncRNA-ROR serves as an oncoRNA that regulates its target by blocking the binding of histone methyltransferase G9A to its target gene ${ }^{13}$. LncRNA GAU1 overexpression in retinoblastoma cisactivates the expression of its target gene GALNT8 to induce retinoblastoma tumorigenesis ${ }^{14}$. LncRNA CANT1 is a novel tumor suppressor in uveal melanoma and activates a novel CANT1-JPX/FTX-XIST long noncoding pathway by directly binding to the promoters of lncRNAs $J P X$ and FTX and restoring the histone H3K4 methylation of their promoters ${ }^{15}$. Thus, correcting lncRNA-guided abnormalities may become an attractive strategy for controlling human malignancies.

Retinoblastoma is an aggressive childhood malignancy of the developing retina that is initiated by the mutation of both $R B$ alleles, thus leading to the functional loss of $\mathrm{RB}$ protein $(\mathrm{pRB})^{16,17}$. Following the $R B$ mutation in the retinoblastoma, other important factors, including genetic and epigenetic alterations, contribute to tumor formation $^{18}$. It has been reported that pRB inactivation collaborates strongly with $M Y C N$ overexpression, giving rise to retinoblastoma in mice ${ }^{19,20}$. In addition, epigenetic alterations may drive retinoblastoma formation by inducing histone $\mathrm{H} 3 \mathrm{~K} 4$ trimethylation and $\mathrm{H} 3 \mathrm{~K} 9 / \mathrm{H} 3 \mathrm{~K} 14$ acetylation of the spleen tyrosine kinase $(S Y K)$ oncogene promoter and activate its expression, which is required for tumor cell survival ${ }^{21}$. These findings reveal the mechanisms underlying rapid retinoblastoma progression following $R B 1$ inactivation and provide a basis for further investigation of new regulatory mechanisms and promising therapeutic approaches for RB tumor progression.

Here, we successfully identified that lncRNA CANT1 functions as a noncoding RB suppressor. Using epigenetic approaches, we found that lncRNA CANT1 acts as a necessary suppressor playing a vital regulatory role in $\mathrm{RB}$ tumorigenesis and we identified a novel type of histone modification that inhibits $P I 3 K \gamma$ transcription.

\section{Materials and methods Cell culture}

Human 293T cells (obtained from ATCC) were cultured in DMEM (GIBCO, USA) and human retinal pigment epithelial cell line ARPE19 (obtained from ATCC) was cultured in DMEM/F12 medium (GIBCO, USA) ${ }^{22,23}$.
The retinoblastoma cell lines Y79 (obtained from ATCC), Weri-Rb1 (obtained from ATCC), and RB44 (kindly provided by Heping $\mathrm{Xu}$, Central South University, Changsha, China) were cultured in RPMI-1640 medium $(\text { GIBCO, USA })^{24-26}$. All media were supplemented with $10 \%$ fetal bovine serum (GIBCO, USA), $1 \%$ penicillin and streptomycin, and cells were incubated at $37^{\circ} \mathrm{C}$ in a humidified $5 \% \mathrm{CO}_{2}$ atmosphere.

\section{Bioinformatics analysis}

LncRNA profiling data are available via the Gene Expression Omnibus (GEO): GSE111168 ${ }^{14}$. Total RNA from lncRNA CANT1-knockdown RB and control RB cells was isolated and quantified. The concentration of each sample was measured by a NanoDrop 2000 (Thermo Scientific, USA). The quality was assessed by an Agilent2200 (Agilent, USA). The sequencing library of each RNA sample was prepared by using an Ion Proton Total RNA-Seq Kit v2 according to the protocol provided by the manufacturer (Life Technologies, USA).

\section{Real-time quantitative polymerase chain reaction (RT- qPCR)}

Total RNA was extracted using TRIzol Reagent (ThermoFisher Scientific, USA) according to the manufacturer's instructions. For the analysis of mRNA expression, cDNA synthesis was performed using the PrimeScript RT Reagent Kit with gDNA Eraser (Takara Biomedical Technology, Beijing, China). PCR analysis was performed using KlenTaq I mix, and amplified PCR products were quantified and normalized using GAPDH as a control. The PCR cycle parameters for lncRNA CASC15 and lncRNA CANT1 expression were as follows: 40 cycles of denaturation at $95^{\circ} \mathrm{C}$ for $30 \mathrm{~s}, 65^{\circ} \mathrm{C}$ for $30 \mathrm{~s}$, extension at $72^{\circ} \mathrm{C}$ for $30 \mathrm{~s}$, and a final extension at $72{ }^{\circ} \mathrm{C}$ for $5 \mathrm{~min}$. RT qPCR was performed using the SYBR Premix ExTaq (Takara Biomedical Technology, Beijing, China) under standard conditions according to the manufacturer's instructions and also normalized using GAPDH as a control. The primers are listed in Supplementary Table S1.

\section{Plasmid construction and lentivirus packaging}

The lncRNA CANT1 plasmid was constructed as previously described ${ }^{15}$. The $293 \mathrm{~T}$ cells were transfected using Lipofectamine 2000 reagent (Invitrogen, USA) with $3 \mu \mathrm{g}$ CMV-CANT1, $3 \mu \mathrm{g}$ pMD2.D, and $6.0 \mu \mathrm{g}$ PsPax. The medium was replaced with $10 \mathrm{~mL}$ of fresh DMEM after $6 \mathrm{~h}$. The virus-containing supernatants were collected at 48 and $72 \mathrm{~h}$ after transfection and then mixed and filtered through a $0.45 \mu \mathrm{m}$ cellulose acetate filter (Sartorius, German). The viral supernatants were concentrated with Amicon Ultra-15 Centrifugal Filter Units (Millipore, USA) and spun at $5000 \mathrm{rpm}$ for $30 \mathrm{~min}$. Colonies were 
selected for subsequent culturing after incubation with $4 \mu \mathrm{g} / \mathrm{mL}$ puromycin for 4 weeks.

\section{Western blot analysis}

Total protein was extracted using RIPA lysis buffer (Beyotime Biotechnology, Shanghai, China), and the protein concentration was determined using a BCA Kit (Beyotime Biotechnology, Shanghai, China). Equal amounts of protein were separated by sodium dodecyl sulfate-polyacrylamide gel electrophoresis (SDS-PAGE) and transferred to polyvinylidene difluoride membrane (Millipore, USA). The membrane was blocked with 5\% nonfat milk for $1 \mathrm{~h}$ and incubated with primary antibodies overnight at $4{ }^{\circ} \mathrm{C}$, followed by secondary antibodies for $1 \mathrm{~h}$ at room temperature. Protein bands were detected using a BIO-RAD imaging system (BIO-RAD, Hercules, CA, USA). The following antibodies were used: anti-PI3Ky (1:1000 dilution; CST 5405S), anti-AKT (1:1000 dilution; CST 4691S), anti-phospho-AKT (Ser473) (1:2000; CST 4060S), and anti-GAPDH (1:10000 dilution; Sigma G9295).

\section{siRNA transfection}

PI3KY and negative control siRNAs were designed and synthesized by Biomics (Shanghai, China). Y79 and Weri$\mathrm{Rb} 1$ cells were transfected using Lipofectamine 2000 (Invitrogen, USA) according to the manufacturer's protocol. Briefly, the cells were seeded at $2 \times 10^{5}$ cells per well in 6-well plates and transfected with 125 pmol of siRNA (target gene or negative control) using Lipofectamine 2000 in Opti-MEM I Reduced Serum Medium (GIBCO, USA). After $48 \mathrm{~h}$ of transfection, the cells were harvested in TRIzol for RNA isolation or lysed in RIPA lysis buffer for Western blotting. Twenty-four hours after transfection, the cells were harvested by centrifugation and used for tumor assays.

\section{CCK8 cell viability assay}

Cells were seeded at a density of 2000 cells per well in flat-bottomed 96-well plates. At the end of the incubation time, $10 \mu \mathrm{l}$ of Cell Counting Kit-8 (CCK-8; Dojindo) solution was added to each well. After $4 \mathrm{~h}$, the optical density at $450 \mathrm{~nm}$ was determined using a microplate reader (Varioskan Flash; Thermo, USA), and the absorbance values were normalized to the values of the cells at $0 \mathrm{~h}$.

\section{Soft agar assay}

A volume of $1 \mathrm{~mL}$ of $0.6 \%$ agar in the complete medium was spread in each well of a 6-well plate; 5000 cells were suspended in $1.0 \mathrm{~mL}$ of $0.3 \%$ agar complete medium and seeded into the upper layer. The cells were cultured with $300 \mu \mathrm{L}$ of complete medium for 4 weeks. The colonies in soft agar were stained with $0.005 \%$ crystal violet and then photographed.

\section{Mouse xenograft experiments}

All procedures were conducted in accordance with the ARVO Statement for the Use of Animals in Ophthalmic and Vision Research. All animals were cared for according to the guiding principles in the care and use of animals. The animal experiments were approved by the Animal Care and Use Committee at Shanghai JiaoTong University School of Medicine. All experiments conform to the guide for care and use of laboratory animals published by the National Insitutes of Health (NIH Publication 85-23, revised in 1996).

For xenograft experiments, 4-week-old male BALB/c nude mice were used. Mice were randomly divided into two groups: the Weri-Rb1 group ( $N=7$ eyes) and the Weri-Rb1-CANT1 group ( $N=7$ eyes). The method for the inoculation of tumor cells into the posterior segments of the eye was as follows: nude mice were anaesthetized by intraperitoneal injection of a ketamine (final concentration: $10 \mathrm{mg} / \mathrm{mL}$ ) and xylazine (final concentration: $1 \mathrm{mg} /$ $\mathrm{mL})$ mixture $(0.01 \mathrm{~mL} / \mathrm{g}$ mouse weight $)$ and with alcaine ocular surface anesthesia. Under a surgical microscope, a sharp 30-gauge needle was used to make two holes through the sclera, one into the intravitreal space to reduce intraocular pressure and one tangentially through the sclera into the subretinal space for injection. RB cells $\left(1 \times 10^{6}\right)$ were injected through the second hole into the choroid and subretinal space using a $1.5 \mathrm{~cm}, 33$-gauge blunt end microinjection needle (7803-05, Hamilton, Reno, NV, USA). After the injection, eyes were covered with ophthalmic bacitracin ointment and buprenorphine was administered for relieving pain relief.

\section{Immunohistochemistry (IHC)}

Tissues were embedded in paraffin, deparaffinized with xylene and rehydrated. Antigen retrieval was performed by heating in sodium citrate buffer ( $\mathrm{pH}$ 6.0). The sections were blocked with $3 \%$ hydrogen peroxide for $20 \mathrm{~min}$ and then in $10 \%$ goat serum for $5 \mathrm{~min}$. For tissue microarray immunohistochemical staining, tissues sections were incubated at $4{ }^{\circ} \mathrm{C}$ overnight with a rat anti-human PI3Ky antibody (CST, USA) at a dilution of 1:100. Tissues were then rinsed in PBST (PBS containing 0.05\% Triton X100), and biotinylated anti-rat secondary antibody was added at a 1:500 dilution and incubated at room temperature for $1 \mathrm{~h}$. After washing twice with PBST, the slides were incubated with streptavidin-horseradish peroxidase (BD Biosciences, USA) and diaminobenzidine substrate for colorimetric development.

\section{Cytoplasmic and nuclear RNA isolation}

Cytoplasmic and nuclear RNA was extracted using Thermo Fisher BioReagents (Thermo Fisher, USA) according to the manufacturer's instructions. RT-qPCR was performed to amplify the localized lncRNA CANT1 
as follows: $1 \mu \mathrm{L}$ of $3 \times$ Klen-Taq I Mix, $1 \mu \mathrm{L}$ of cDNA, and $0.5 \mu \mathrm{L}$ of each $10 \mu \mathrm{M}$ primer were combined under liquid wax. After incubation at $95^{\circ} \mathrm{C}$ for $2 \mathrm{~min}$, the cDNA was amplified with 40 cycles of $95^{\circ} \mathrm{C}$ for $30 \mathrm{~s}, 65^{\circ} \mathrm{C}$ for $30 \mathrm{~s}$, and $72^{\circ} \mathrm{C}$ for $30 \mathrm{~s}$ (extension), and with a final extension at $72{ }^{\circ} \mathrm{C}$ for $5 \mathrm{~min}$.

\section{RNA Fish}

RNA FISH was performed using a fluorescent in situ hybridization kit (RiboBio, China) following the manufacturer's instructions. The lncRNA CANT1 probes were designed and synthesized by the RiboBio Company. Briefly, cells were collected after transfection with the corresponding vector for $48 \mathrm{~h}$ and subsequently seeded on glass coverslips. Fluorescence detection was performed with a microscope (BX41; Olympus, Japan).

\section{Chromatin oligonucleotide precipitation (ChOP)}

The ChOP assay was performed as previously described $^{15}$. Cells were fixed using $1 \%$ formaldehyde (SigmaAldrich, USA) for $10 \mathrm{~min}$ at room temperature and centrifuged at $3000 \mathrm{rpm}$ for $15 \mathrm{~min}$. The pellet was suspended in $300 \mu \mathrm{L}$ of buffer A (10 mM Tris- $\mathrm{HCl}, \mathrm{pH} 7.4,10 \mathrm{mM}$ $\mathrm{NaCl}, 3 \mathrm{mM} \mathrm{MgCl}$, and $0.5 \% \mathrm{v} / \mathrm{v} \mathrm{NP}-40$ ) and incubated for $15 \mathrm{~min}$ on ice. The nuclei were harvested in $150 \mu \mathrm{L}$ of buffer B (50 mM Tris- $\mathrm{HCl}, \mathrm{pH}$ 7.9, 0.5 mM PMSF, 0.1\% SDS, $10 \mathrm{mM}$ EDTA, $100 \mathrm{U} / \mathrm{mL}$ RNase, and protease inhibitors) and incubated on ice for $10 \mathrm{~min}$. An equal volume of buffer C (15 mM Tris- $\mathrm{HCl}$, pH 7.9, $1 \mathrm{mM}$ EDTA, $1 \%$ Triton X-100, $150 \mathrm{mM} \mathrm{NaCl}, 0.5 \mathrm{mM}$ PMSF, $100 \mathrm{U} / \mathrm{mL}$ RNase, and protease inhibitors) was added, and the samples were sonicated (10 s on, $15 \mathrm{~s}$ off, output $30 \%$, $4 \mathrm{~min})$. Sonicated DNA was found to be enriched in the range of $200-500 \mathrm{bp}$. After centrifugation, $150 \mu \mathrm{L}$ aliquots of sonicated chromatin were combined with $100 \mathrm{pmol}$ of either biotinylated antisense oligos against the target RNA or biotinylated scrambled oligos, incubated at an appropriate annealing temperature for $5 \mathrm{~min}$ and then slowly cooled to room temperature. A $50 \mu \mathrm{L}$ volume of beads was used to capture the biotinylated DNA/RNA complexes for $25 \mathrm{~min}$ at room temperature with gentle rotation. After 3 washes, $150 \mu \mathrm{L}$ of diethyl pyrocarbonate (DEPC) water was used for elution at $70^{\circ} \mathrm{C}$ for $5 \mathrm{~min}$. After crosslink reversal and purification, the samples were ready for PCR. A TaqMan assay using the ABI 7500 RealTime PCR System was performed to detect the quality of the lncRNA CANT1 pulled down by Dynabeads MyOne Streptavidin $\mathrm{C} 1$ beads. Primers and probes labeled at their $5^{\prime}$ and $3^{\prime}$ ends with FAM and minor groove binder or black hole quencher-1 were designed to target lncRNA CANT1. The amplification reactions were optimized individually for all of the probes and associated primers. Each reaction was conducted in a total volume of $10 \mu \mathrm{L}$ consisting of $0.25 \mu \mathrm{L}$ of $10 \mathrm{mM}$ dinucleotide triphosphates
(dNTPs), $0.1 \mu \mathrm{L}$ of the TaqMan probe, $0.6 \mu \mathrm{L}$ of $25 \mathrm{mM}$ $\mathrm{MgCl}_{2}, 2 \mu \mathrm{L}$ of $5 \times \mathrm{Q}$ buffer, $0.1 \mu \mathrm{L}$ of $5 \mathrm{U} / \mu \mathrm{L}$ Hotstart, $0.1 \mu \mathrm{L}$ of the reference ROX dye, $0.25 \mu \mathrm{L}$ of each $10 \mu \mathrm{M}$ primer, and $4 \mu \mathrm{L}$ of the template.

\section{Chromatin immunoprecipitation (ChIP)}

ChIP was performed using an EZ-Magna ChIP A/G kit (Millipore) according to the manufacturer's instructions. Anti-hSET1 was purchased from Abcam and antiH3K4me3 was purchased from Millipore. Anti-RNA polymerase-II (pol-II; Millipore) was used as a positive control antibody and normal mouse IgG was used as a negative control. See Supplementary Table S1 for a list of primers for ChIP-qPCR.

\section{Statistical analysis}

Experiments were performed in triplicate when indicated, and the data were presented as the means \pm SEM. The comparative threshold cycle method was applied in the RT-qPCR assay according to the $\Delta \Delta$ threshold cycle method. The differences between two groups were analyzed using the unpaired two-sided Student's $t$ test. A $P$ value $<0.05$ was considered statistically significant.

\section{Results \\ CANT1 IncRNA expression is downregulated in retinoblastoma}

A genome-wide RNA-sequencing analysis of three retinoblastoma tissues and paired normal tissues that we previously reported can be accessed via GEO: GSE111168 ${ }^{14}$. The bioinformatics analysis showed that the level of CASC15 lncRNA was lower in tumor tissues than that in normal tissues (Fig. 1a). We next identified which transcript existed on the chromosome 6p22.3 locus in RB. Different transcripts exist on the chromosome 6p22.3 locus in different tissues, for example, CASC15 is $1902 \mathrm{bp}$ in length with 12 exons according to databases in the University of California, Santa Cruz (UCSC) and National Center for Biotechnology Information (NCBI) databases, and lncRNA CANT1 (GenBank: KP981381.1) is 1114 bp with 7 exons, which was confirmed by our previous research ${ }^{15}$. Therefore, we designed two isoformspecific primers to differentiate the transcripts (Supplementary Fig. S1A). The data showed that lncRNA CANT1 expression was significantly decreased in RB cells compared with normal ARPE19 cells, however, CASC15 was weakly expressed in both ARPE19 and RB cell lines (Fig. 1b). We also further confirmed CANT1 expression by RTPCR (Fig. 1c). To determine the clinical relevance of CANT1 in RB, we collected human RB tissue samples (Table S2) to examine CANT1 expression. The expression of CANT1 was markedly reduced in RB tissues compared with normal tissues (Fig. 1d). These data show that lncRNA CANT1 is alternatively spliced from chromosome 
A

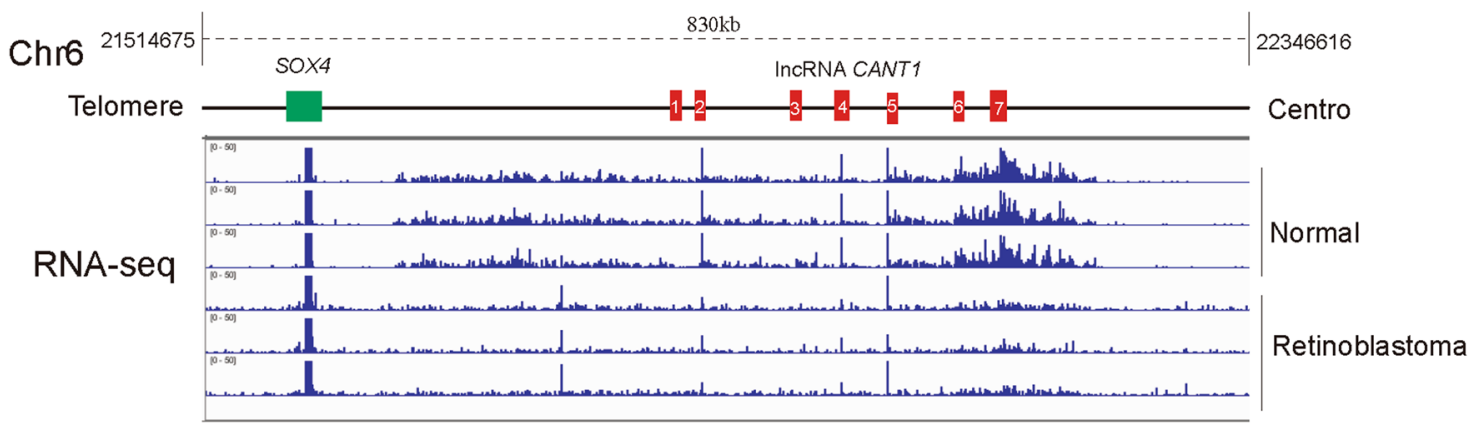

B

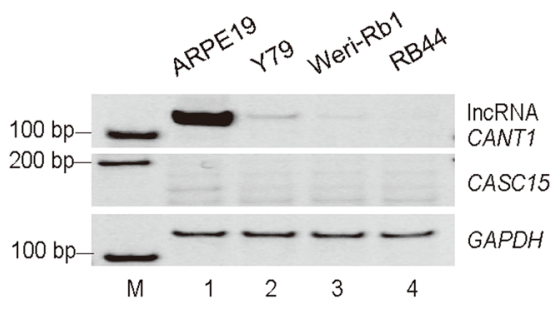

D

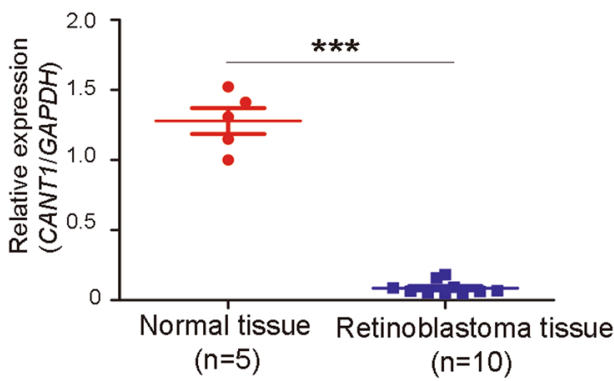

C

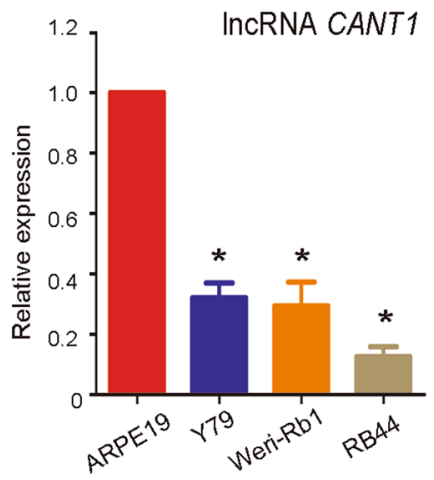

E

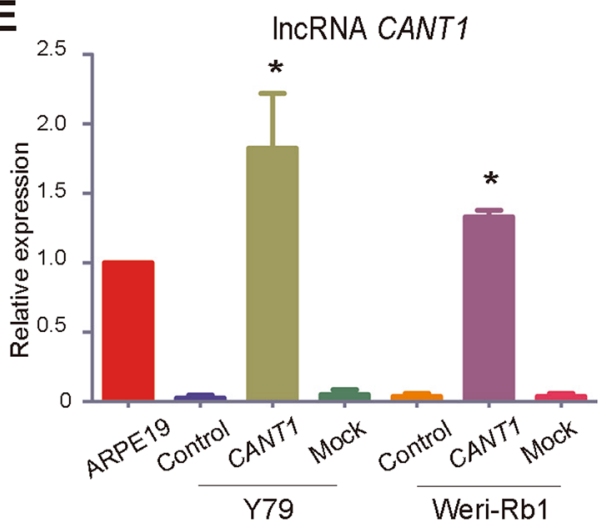

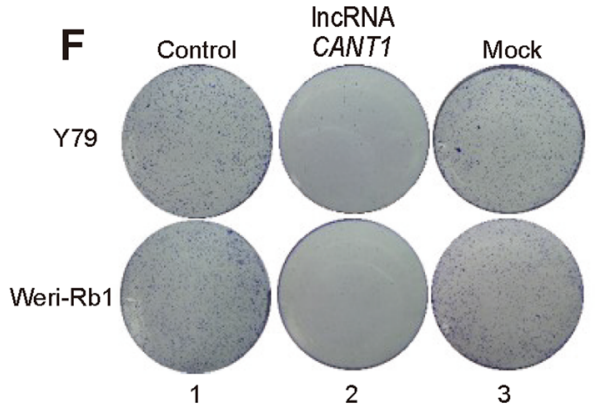

G

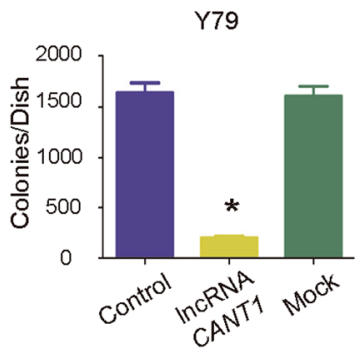

H

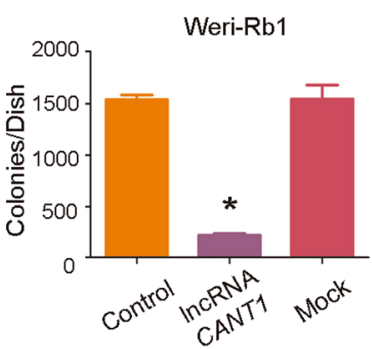

Fig. 1 (See legend on next page.) 
(see figure on previous page)

Fig. 1 Identification of CANT1 IncRNA. a RNA-sequence analysis was performed to evaluate the transcriptome of three retinoblastoma samples and normal retina samples. Red chart: the exons of IncRNA CANT1. Green chart: normal expression of the SOX4 gene in Chr6p22.3. b Expression of CANT1 and CASC15 in three RB cell lines: Y79, Weri-Rb1, and RB44. ARPE19 cells were used as normal control. GAPDH was used as the internal control; M: marker. c Real-time PCR was performed to show CANT1 expression level in RB cells; data are presented as the mean \pm SEM. ${ }^{*} P<0.05$ compared with ARPE19. $\mathbf{d}$ Real-time PCR examination of CANT1 expression in RB tissue. Normal tissues were used as a control. The relative values were normalized to the GAPDH expression level and are presented as mean \pm SEM. ${ }^{* * *} P<0.001$. e Real-time PCR showing overexpression of CANT1 in RB cell lines Y79 and Weri-Rb1. Wild-type tumor cells were used as control. Mock, an empty vector. Data are presented as the mean \pm SEM. ${ }^{*} P<0.05$ compared with the respective control. $\mathbf{f}$ A colony formation assay was performed to assess the tumor growth of RB cells. $\mathbf{g}, \mathbf{h}$ Colony numbers of Y79 ( $\mathbf{g}$ ) and Weri$\mathrm{Rb} 1$ (h) cells were counted in three independent plates. All of the data are presented as the mean $\pm \mathrm{SEM}$. ${ }^{*} P<0.05$ : compared with the control.

$6 \mathrm{p} 22.3$ and is likely to play an unknown role in $\mathrm{RB}$ tumorigenesis.

To explore the potential role of CANT1 in RB, we overexpressed lncRNA CANT1 in RB cell lines. Therefore, we constructed a plasmid containing the full-length CANT1 sequence and packaged it in a lentivirus for transfection into Y79 and Weri-Rb1. As expected, lncRNA CANT1 was successfully overexpressed in Y79 and Weri-Rb1 cells (Fig. 1e).

\section{CANT1 modulates RB tumorigenesis in vitro and in vivo}

We next investigated whether the $\mathrm{RB}$ tumor characteristics were altered after CANT1 overexpression. In a colony formation assay, the number of colonies of CANT1-overexpressing Y79 cell (Fig. 1f upper and Fig. 1g) and Weri-Rb1 cell (Fig. 1f bottom and Fig. 1h) colonies was significantly reduced. In addition, we used a CCK8 assay to evaluate tumor cell growth. As expected, the $\mathrm{RB}$ cell growth rate was significantly lower than the wide-type RB cell growth rate (Fig. 2a, b). Next, we used a classical soft agar assay to examine tumor formation ability in vitro. We observed that tumor colonies were markedly smaller than those formed by wild-type tumor cells and mock cells (Fig. 2c). In addition, the statistical analysis confirmed that the number of colonies formed by the two tumor cells types was greatly reduced by CANT1 overexpression in vitro (Fig. $2 \mathrm{~d}$ ).

To examine the ability of CANT1 to suppress tumor formation in vivo, we inoculated CANT1-overexpressing Weri-Rb1 cells and mock cells into the posterior segments of the eyes of nude mice. Extraocular tissue was removed, and the tumor-bearing eye mass was measured. As expected, the eye mass weight in the CANT1-overexpressing group was reduced by $48 \%\left(n=7,{ }^{*} P<0.05\right.$; Fig. 2e, Supplementary Fig. S2A), and the eye mass exhibited a marked reduction in size (Fig. 2f). These results demonstrate that the lncRNA CANT1 serves as a tumor suppressor that modulates tumor formation in RB.

\section{CANT1 modulates PI3Ky/Akt signaling in RB}

To elucidate the mechanism underlying the suppressive role of CANT1 in RB expansion, we employed RNA transcriptome-sequencing (GEO Accession number: GSE141327) to analyze CANT1-overexpressing cells and control Y79 and Weri-Rb1 cells. We found differentially expressed genes (fold change $\geq 1.5$, false discovery rate $<0.05$ ) in both cell lines, with 12 genes upregulated and 454 genes downregulated (Fig. 3a). The Gene Ontology (GO) analysis showed that the most significantly overrepresented biological processes included pathways involved in oxygen transport, regulation of cell population proliferation, as well as signal transduction (Supplementary Fig. S3A). The Kyoto Encyclopedia of Genes and Genomes (KEGG) analysis demonstrated that several pathways, including the NF- $\mathrm{B}$ s signaling pathway and PI3K/Akt signaling pathways, were altered (Fig. 3b). Then, we focused on the differentially expressed genes in PI3K/Akt signaling pathway (Fig. 3c) and examined the expression of PI3K $\gamma$ (also called PIK3CG, gene ID: 5294; one of the most important genes in PI3K/Akt signaling) in tumor cells and in normal ARPE19 cells. The RNA-sequence analysis showed that there was almost no transcription at the PI3Kr locus in CANT1-overexpressing RB cells (Supplementary Fig. S3B). As expected, at the mRNA level, PI3Ky expression was upregulated more than 10-fold in Y79 cells and approximately 20-fold in Weri-Rb1 cells, compared with that in normal ARPE19 cells (Fig. 3d). The Western blot data confirmed that the protein expression of $P I 3 K \gamma$ in $\mathrm{RB}$ tumor cells was markedly increased compared to that of normal ARPE19 cells, which displayed extremely weak PI3K $\gamma$ expression (Fig. 3e, lane1, lane 4, and lane 7). However, in CANT1-overexpressing RB cells, both mRNA (Fig. 3d) and protein (Fig. 3e, lane 2 and lane 5) levels of $P I 3 K \gamma$ were significantly reduced. We also examined the activation of Akt, downstream of PI3K $\gamma$. The Akt phosphorylation level decreased in accordance with the PI $3 K \gamma$ expression level. An $\mathrm{IHC}$ staining was then performed to detect $\mathrm{PI} 3 \mathrm{~K} \gamma$ protein expression in RB tissues compared with normal retina. The results clearly showed that $\mathrm{PI} 3 \mathrm{~K} \gamma$ protein was remarkably increased in the human RB tissues (Fig. 3f). The staining of $\mathrm{PI} 3 \mathrm{~K} \gamma$ in the mouse Weri-Rb1-mock eyes was also darker than that in the Weri-Rb1-CANT1 eyes obtained from the mouse experiments (Supplementary Fig. S3C). Taken together, these data demonstrate that $P I 3 K \gamma$ may act as a potential target of the lncRNA CANT1. 


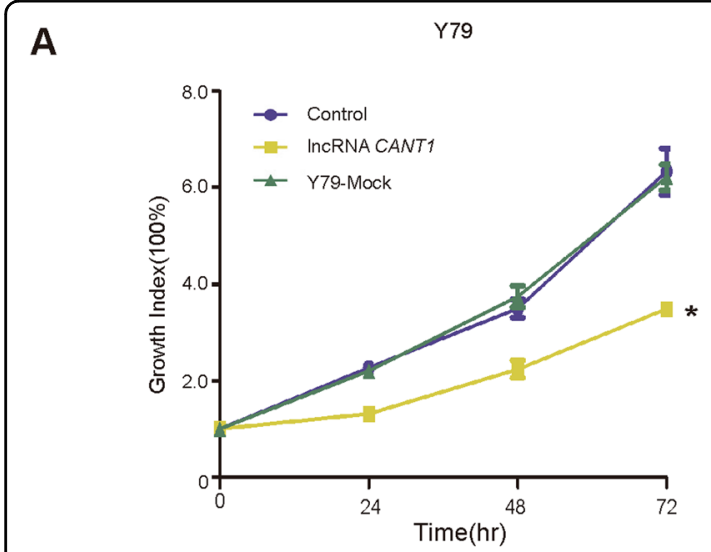

B

Weri-Rb1
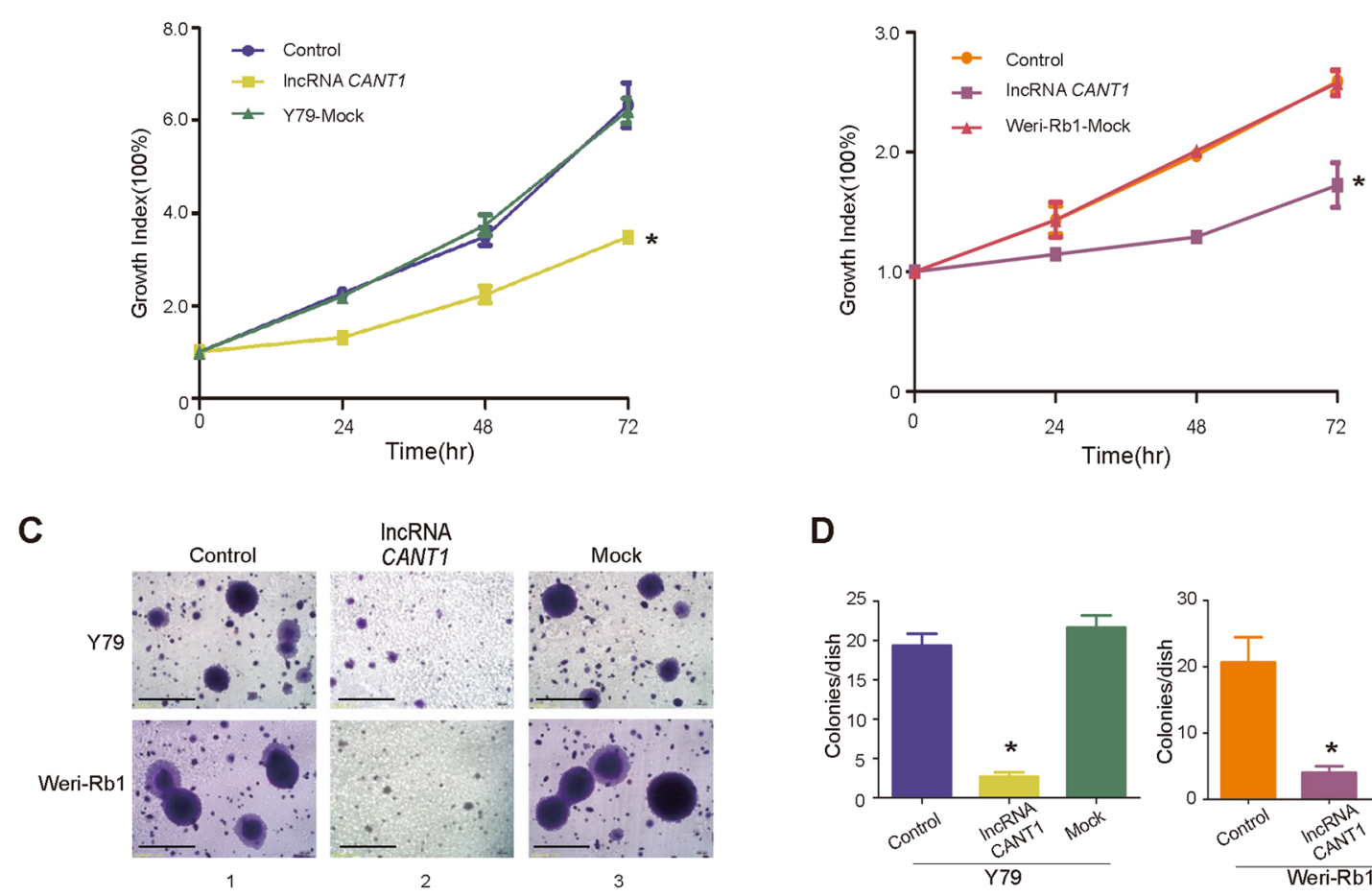

D
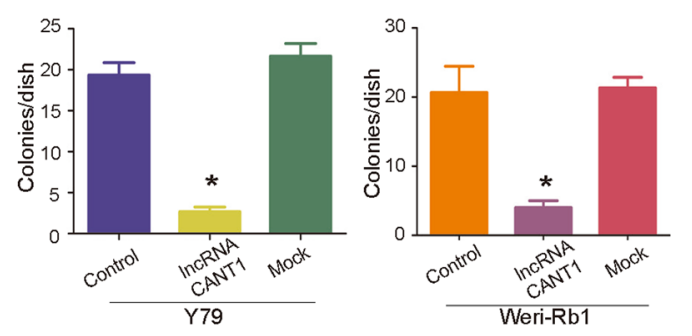

E

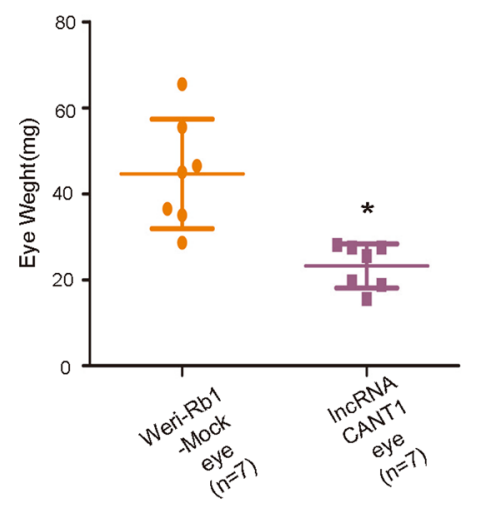

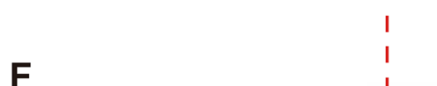

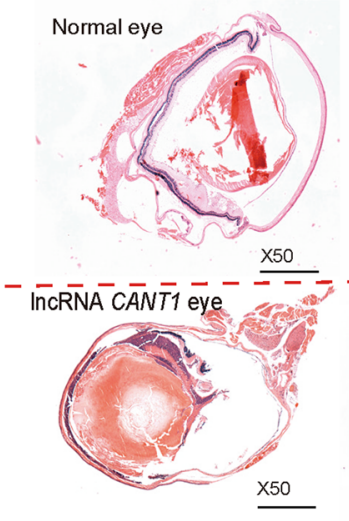

Fig. 2 Functional roles of CANT1 IncRNA in RB. a, b A CCK8 assay was performed to measure the cell growth rate of CANT1-overexpressing Y79 and Weri-Rb1 cells. The experiments were performed in triplicate, and the absorbance at day 1 was set as $100 \%$. ${ }^{*} P<0.05$ compared with the control and mock. c, d A soft agar assay was used to assess the tumor formation ability in vitro. c Small colonies were observed and counted under the microscope. $\mathbf{d}$ Colony count statistics showed a significant reduction in colonies formed by CANT1-overexpressing cells. Colony numbers were counted in three independent soft agar plates. All of the data are presented as the mean \pm SEM. ${ }^{*} P<0.05$ compared with the control and mock. Scale bar: $600 \mu \mathrm{m}$. e, $\mathbf{f}$ Eye weight of the orthotropic xenograft formed by Weri-Rb1 cells injected into the vitreous cavity with or without CANT1 overexpression at 40 days after implantation; $n=7,{ }^{*} P<0.05$ compared with the mock. $\mathbf{f}$ Representative images of H\&E staining for the evaluation of tumor formation in vivo. Scale bar: $200 \mu \mathrm{m}$. 


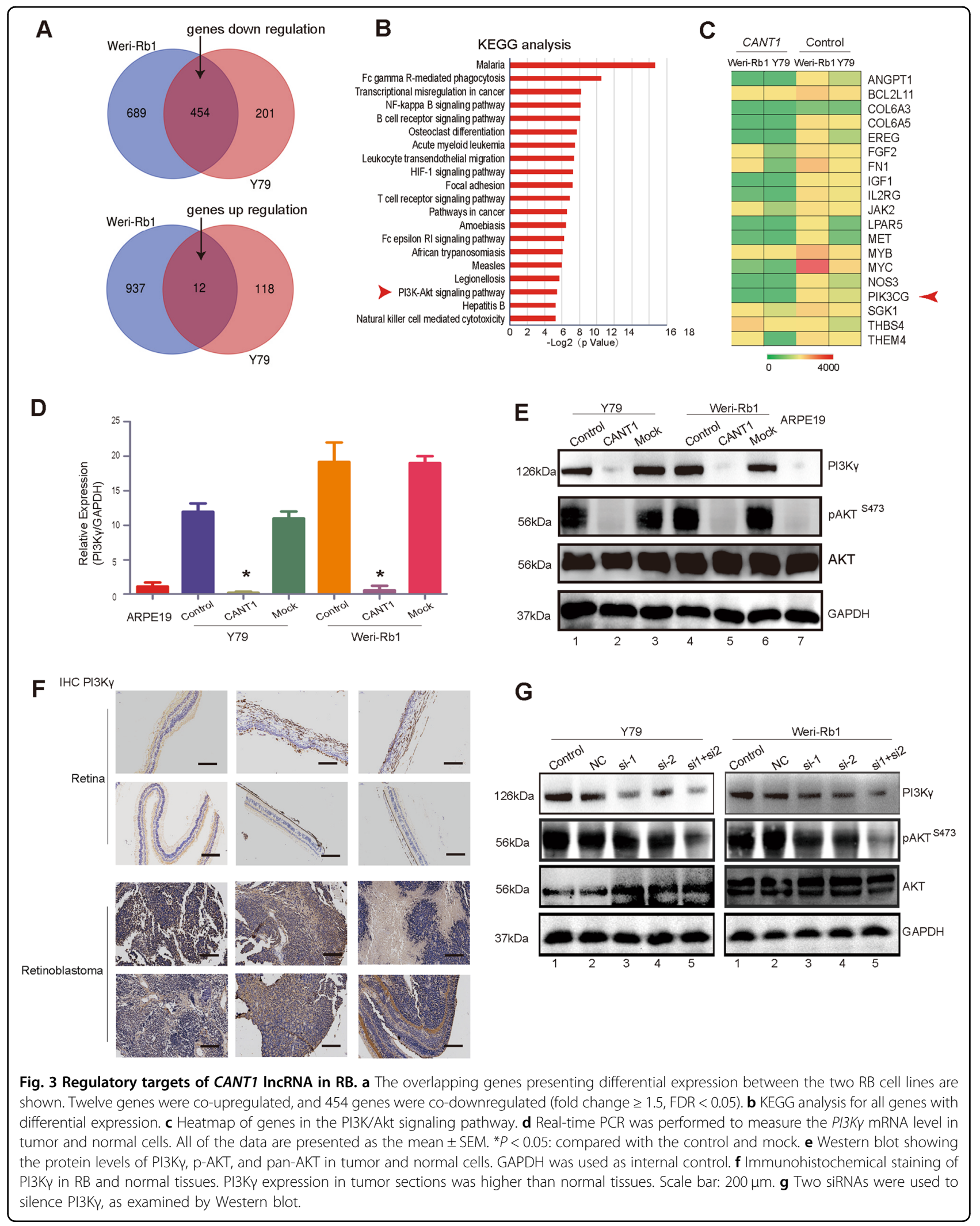




\section{$\mathrm{PI} 3 \mathrm{~K} \gamma$ is required for $\mathrm{RB}$ tumorigenesis}

To further investigate the role of $P I 3 K \gamma$ in $\mathrm{RB}$, we used the classic RNAi method to silence $P I 3 K \gamma$ expression in RB cells. Three siRNAs (siPI3K $\gamma-1$, siPI $K \gamma-2$, and si $P I 3 K \gamma-3)$ were designed to test the efficiency of silencing. The results showed that both siPI3K $\gamma-1$ and si $P I 3 K \gamma-2$ worked and an siPI3K $\gamma$-mix that combined si $P I 3 K \gamma-1$ and si $P I 3 K \gamma-2$ was more efficient than the two siRNAs alone in knocking down PI3K $\gamma$ expression at the mRNA transcript level (Supplementary Fig. S4A, B). si $P I 3 K \gamma$-1, si $P I 3 K \gamma$-2, and siPI3K $\gamma$-mix were able to knock down the PI3K $\gamma$ protein and silence PI3K/Akt signaling in the two RB cell lines (Fig. 3g). Intriguingly, lncRNA CANT1 expression was not notably changed when $P I 3 K \gamma$ was depleted (Supplementary Fig. S4C, D). These data support our hypothesis that diminished $P I 3 K \gamma$ expression is triggered by CANT1 upregulation and $P I 3 K \gamma$ acts as a regulatory target of lncRNA CANT1.

To further define the role of $P I 3 K \gamma$ in tumor formation, we chose si $P I 3 K \gamma$-mix for subsequent experiments. In the CCK8 assay, the proliferation of PI3K $\gamma$-knockdown RB cells was found to be significantly decreased (Fig. 4a, b). A colony quantification assay showed that the number of colonies was markedly reduced by siRNA treatment in Y79 and Weri-Rb1 cells (Fig. 4c, d). Furthermore, through a soft agar assay, we found that the in vitro colony formation ability of RB cells was significantly reduced by $P I 3 K \gamma$ inactivation (Fig. 4e, f). These data show that PI3K $\gamma$ may act as an oncogene in RB progression and its attenuation may mediate the antitumor effect of CANT1 in RB tumorigenesis.

\section{CANT1 directly binds to the PI3KY promoter}

Using U2 snRNA as a positive control for nuclear fraction and GAPDH as a control for the cytosolic fraction, we found that CANT1 was located mainly in the nucleus in CANT1-overexpressing Y79 and Weri-Rb1 cells (Fig. 5a). RNA fluorescence in situ hybridization (RNA FISH) further confirmed that CANT1 was mainly distributed in the nucleus (Fig. 5b). In addition, RNA FISH demonstrated that CANT1 RNA was abundant in the cell nucleus of human retina tissues, whereas very weak signals were observed in human retinoblastoma tissues (Fig. 5c). These data suggest that CANT1 is a nuclear lncRNA in RB cells and might guide $P I 3 K \gamma$ regulation via a chromosome-related mechanism. To explore the mechanism by which CANT1 regulates the expression of $P I 3 K \gamma$, we used a classical ChOP assay. We designed two biotin-labeled, short oligonucleotides aligned with CANT1 (Fig. 5d, upper). Site a (300 bp upstream of the $P I 3 K \gamma$ TSS) was used to detect the promoter region of $P I 3 K \gamma$ and site b was used as nonspecific promoter region (Fig. 5d, bottom). After pull-down, we found that CANT1 bound strongly to the $P I 3 K \gamma$ promoter in two CANT1overexpressing cell lines (Fig. 5e, f, lane 3 and lane 6), whereas this DNA-RNA interaction was not observed in the control or mock-transfected cells (Fig. 5e, f, lane 2, lane 4, lane 5, and lane 7). We also used a random oligonucleotide as a negative control because it did not bind to the $P I 3 K \gamma$ promoter in either cell line (Fig. 5e, $\mathrm{f}$, lanes 8-10). In addition, to further validate the binding of CANT1 to the PI3K $\gamma$ promoter, we performed an RTqPCR analysis to quantitate the enrichment of CANT1 at the $P I 3 K \gamma$ promoter. The analysis showed that CANT1 binding to the promoter of $P I 3 K \gamma$ was increased compared with that in the controls and mocks (Fig. 5g, h). Taken together, these results demonstrate that CANT1 might regulate $P I 3 K \gamma$ expression by directly binding to key DNA regulatory regions of its promoter.

\section{CANT1 modulates PI3KY expression by abolishing histone H3K4 methylation}

Next, we explored whether epigenetic modifications were altered and whether the histone methylation status was changed at the promoter of the $P I 3 K \gamma$ gene after CANT1 overexpression. Site X was $6 \mathrm{~kb}$ upstream of the $P I 3 K \gamma$ transcription start site (TSS), site Y was $300 \mathrm{bp}$ upstream of the $P I 3 K \gamma$ TSS, and site $\mathrm{Z}$ was the promoter of GAPDH (Fig. 6a). Through a ChIP assay, we found that the H3K4 trimethylation status at the $P I 3 K \gamma$ promoter was significantly decreased after CANT1 overexpression (Fig. 6c). The H3K4 trimethylation status at $6 \mathrm{~kb}$ upstream of the PI3K $\gamma$ TSS (site X) was minimal, whether CANT1 was overexpressed or not (Fig. 6b). H3K4 modification at the GAPDH promoter (site $\mathrm{Z}$ ) was used as a positive control because GAPDH expression was stable in all cell lines (Fig. 6d). The above results were further confirmed by a quantitative ChIP-PCR assay (Fig. 6e, f). Furthermore, we found that there was no significant change in H3K4me3 expression after CANT1 overexpression (Supplementary Fig. S4E), indicating that CANT1 itself does not regulate the activity of $\mathrm{H} 3 \mathrm{~K} 4$ methyltransferase in cell lines and likely regulates $\mathrm{H} 3 \mathrm{~K} 4 \mathrm{me} 3$ of the $P I 3 K \gamma$ promoter by modulating the binding of H3K4 methyltransferase to the target regions of the genome.

\section{CANT1 competes with hSET1 methyltransferase in vitro}

Because hSET and MLL1-4 are H3K4 methyltransferases, we sought to identify which participates in the above process. We used a ChIP assay and found that hSET1 bound to the nearby $P I 3 K \gamma$ promoter in control and mock cells (Fig. $7 \mathrm{~b}$, lane 2 , lane 4 , lane 5 , and lane 7 ), but the recruitment of hSET 1 to the $P I 3 K \gamma$ promoter was markedly inhibited in the two CANT1-overexpressing cell lines (Fig. 7b, lane 3 and lane 6). We used negative ChIP Site X (6 kb upstream of the $P I 3 K \gamma$ TSS) to exclude nonspecific interactions. As expected, hSET1 binding to the PI3K $\gamma$ promoter could not be measured regardless of the CANT1 expression status at site $X$ (Fig. 7a). Similarly, the 


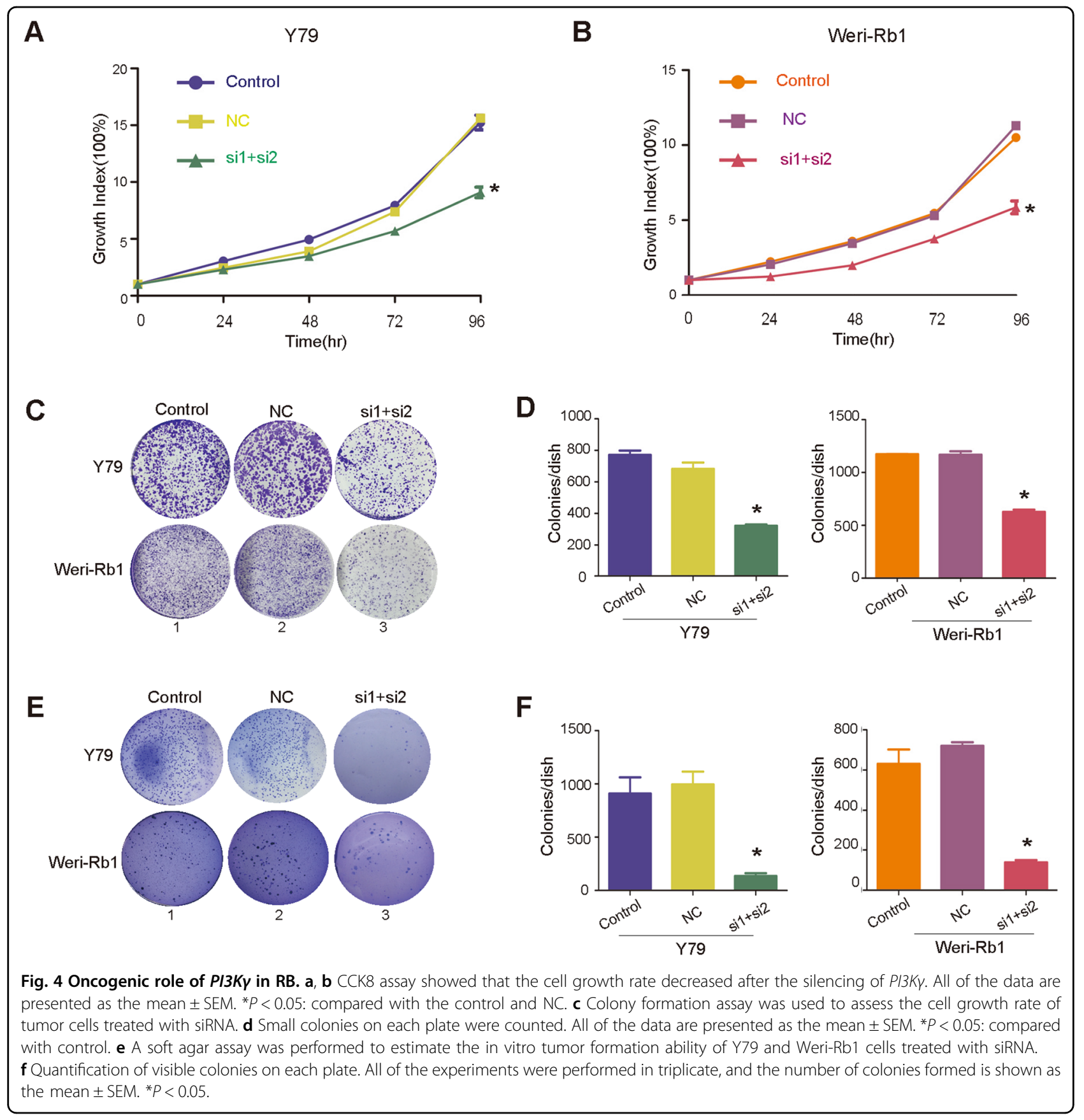

ChIP-qPCR data were consistent with these data (Fig. 7c, d). We also performed an RNA IP assay and found that CANT1 does not bind to the hSET1 protein. Taken together, these results demonstrate that CANT1 blocks the hSET1 methyltransferase from binding to the PI3KY promoter.

\section{Discussion}

Considering that more than $80 \%$ of the genome is transcribed and that the majority of the transcription across the genome is non-coding, the chances of identifying a functional potential noncoding RNA are high ${ }^{27}$. A set of characterization studies has identified the critical roles played by long noncoding RNAs in gene expression regulation, cytoplasmic or nuclear complexes scaffolding, and pairing with other RNAs $^{3,28,29}$. However, the functions of the vast majority of these transcripts remain unknown and deserve further investigation. Herein, we revealed that a novel inactivated IncRNA, CANT1, at chromosome 6p22.3 modulates RB tumorigenesis through the epigenetic activation of $\mathrm{PI} 3 \mathrm{~K} \gamma$ expression, thus enhancing PI3K/Akt signaling and accelerating tumor progression (Fig. 7e). 
A

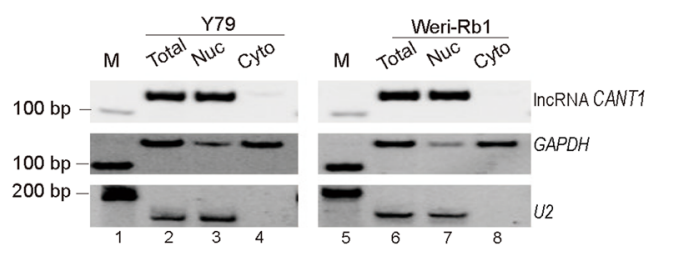

C
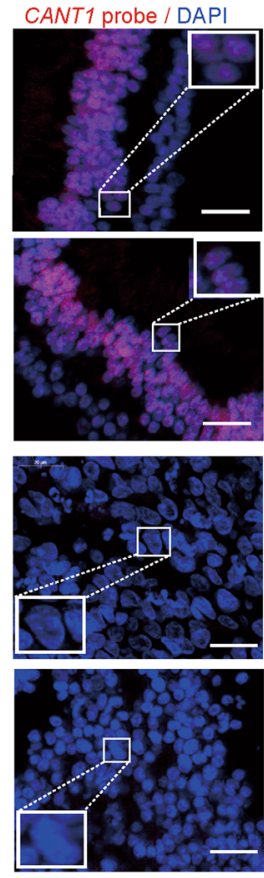

E

Y79

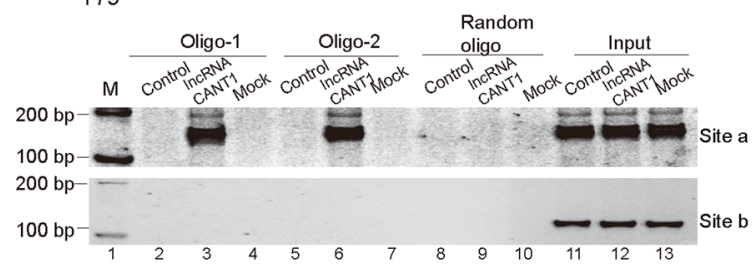

G

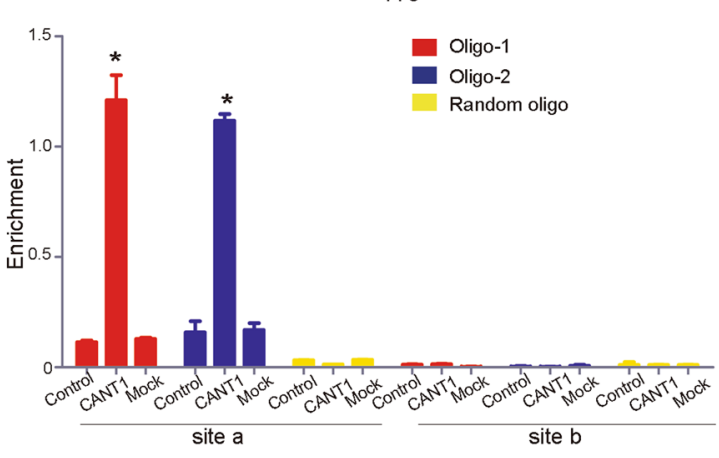

B
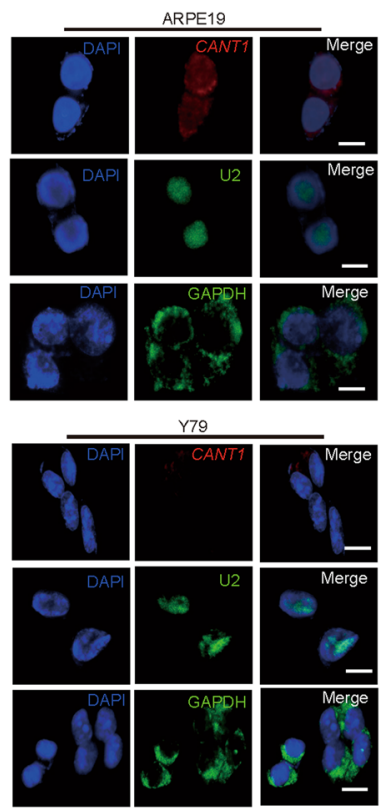

D Oligo-1
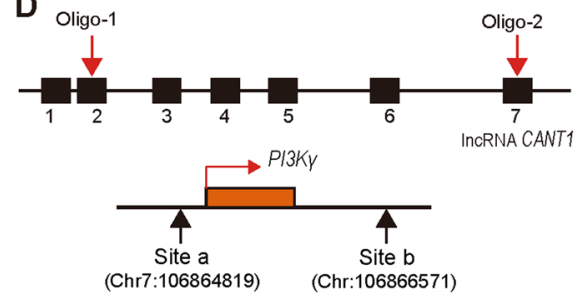

$\mathbf{F}$

Weri-Rb1

Random

Oligo-1 $\quad$ Oligo-2 $\quad \begin{aligned} & \text { Random } \\ & \text { oligo }\end{aligned}$ Input

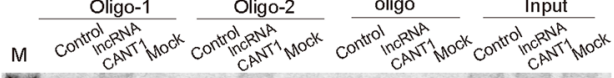

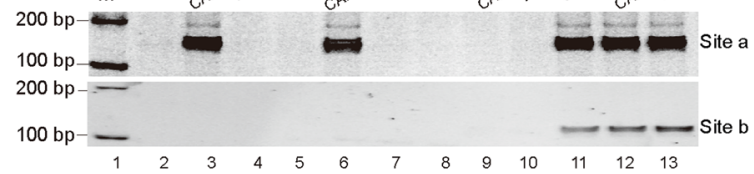

H

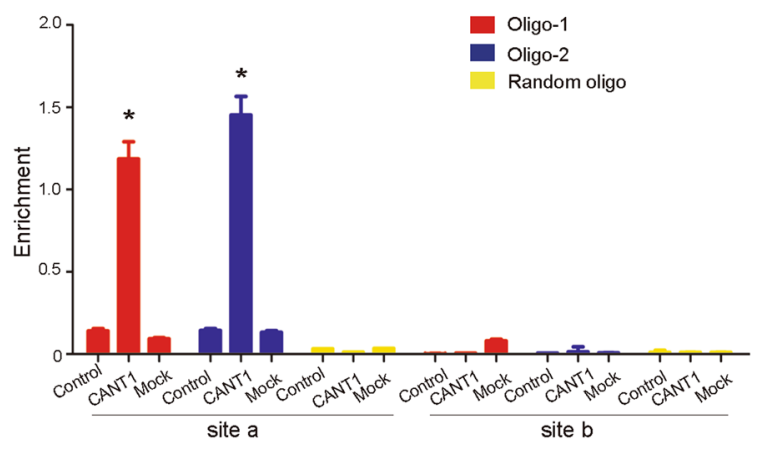

Fig. 5 (See legend on next page.) 
(see figure on previous page)

Fig. 5 CANT1 binds to the promoter of its targets. a The location of mature CANT1. CANT1 is mainly located in the nucleus. U2 RNA was used as a positive control for nuclear RNA, and GAPDH served as a positive control for the cytoplasmic RNA. b Representative RNA FISH images showed that the CANT1 signal overlapped with DAPI staining in ARPE19 cells. The scale bars represent $10 \mu \mathrm{m}$. c RNA-FISH was performed with CANT1 oligos on clinical retinoblastoma samples and normal control samples. Scale bar: $20 \mu \mathrm{m}$. d Schematic diagram of IncRNA CANT1 and the PI3KY promoter region. CANT1 oligo-1 and oligo-2 indicate the biotinylated antisense oligonucleotides targeting IncRNA CANT1. Random oligo indicates the scrambled oligonucleotide used as a negative control in the ChOP assay. e, $\mathbf{f}$ PCR examination of the binding of CANT1 to the PI3KY promoter in the ChOP assay. Site a: CANT1 interacts with the PIBKY promoter. Site b: a negative control locus. Input: Total RNA was reverse transcribed before incubation with labeled CANT1 fragments and amplified with primers for site a and site $\mathbf{b} . \mathbf{g}, \mathbf{h}$ Quantification of the binding of CANT1 to the PI3KY promoter in the ChOP assay by real-time $\mathrm{gPCR}$. The data are presented as mean \pm SEM. ${ }^{*} P<0.05$.

A
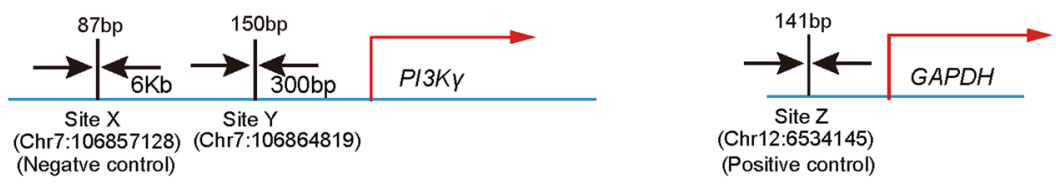

$\longrightarrow$ Transcription start site of gene

B

Site $X$

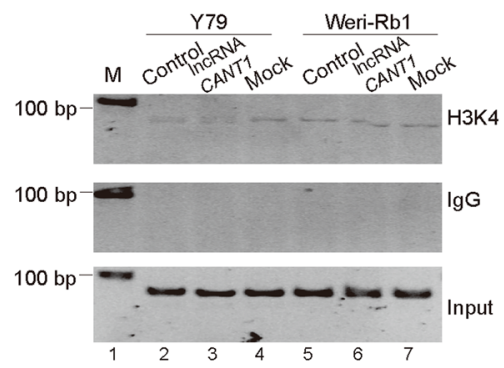

C

Site $Y$

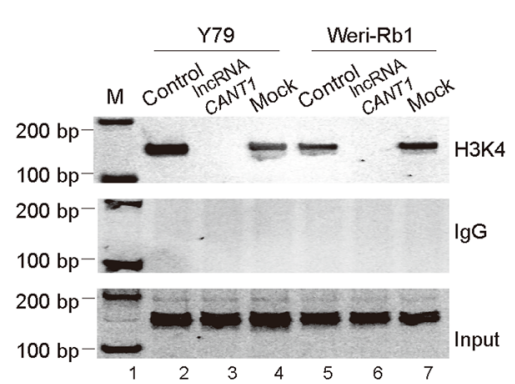

D

Site Z

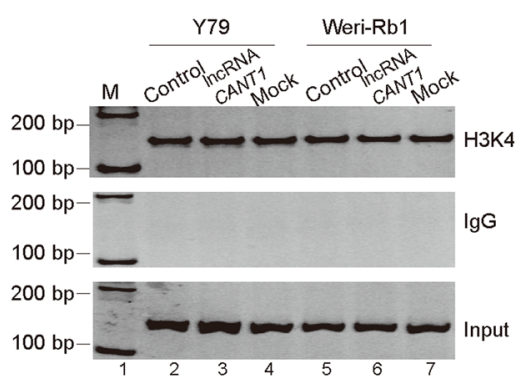

Weri-Rb1
E

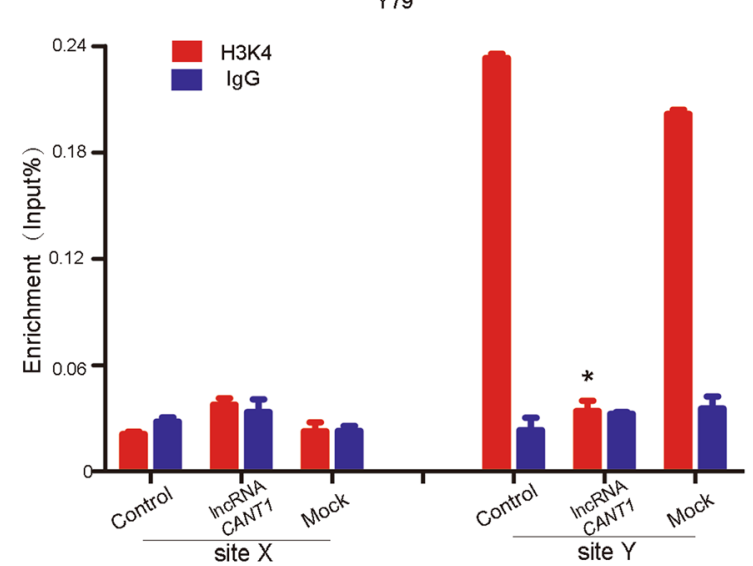

$\mathbf{F}$

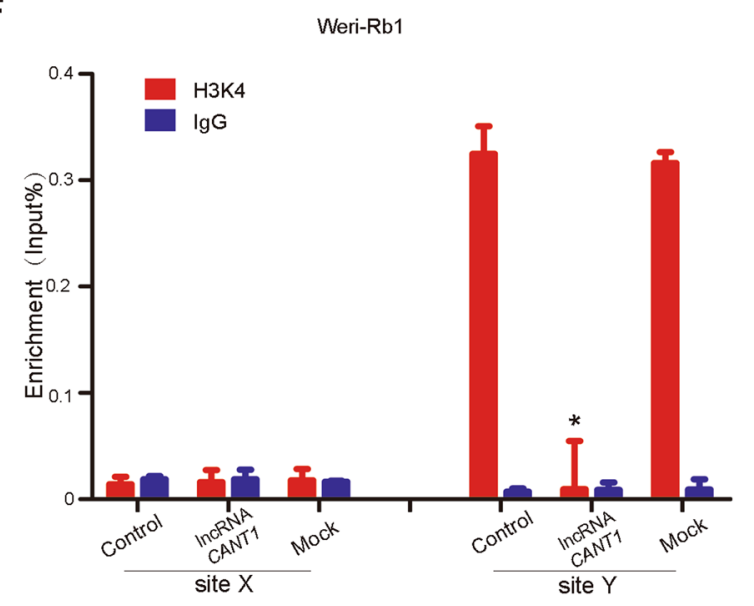

Fig. 6 CANT1 modulates PI3KY transcription by abolishing H3K4 methylation. a Schematic diagram of the PI3KY and the GAPDH promoter regions. Arrow: transcriptional direction; sites X-Z: different sites used in this assay. b-d PCR examination of histone H3K4 trimethylation changes in the PI3KY promoter (c) and GAPDH promoter (d) upon CANT1 overexpression in Y79 and Weri-Rb1 cells. IgG was used as a negative control. Input: total RNA was reverse transcribed before incubation and amplified with primers; M: marker. e, $\mathbf{f}$ Real-time qPCR examination of histone H3K4 trimethylation changes in the PI3KY promoter. Site $X$ is $6 \mathrm{~kb}$ upstream of the PI3KY TSS. All data are presented as the means \pm SEM. ${ }^{*} P<0.05$ : compared with the control and mock. 


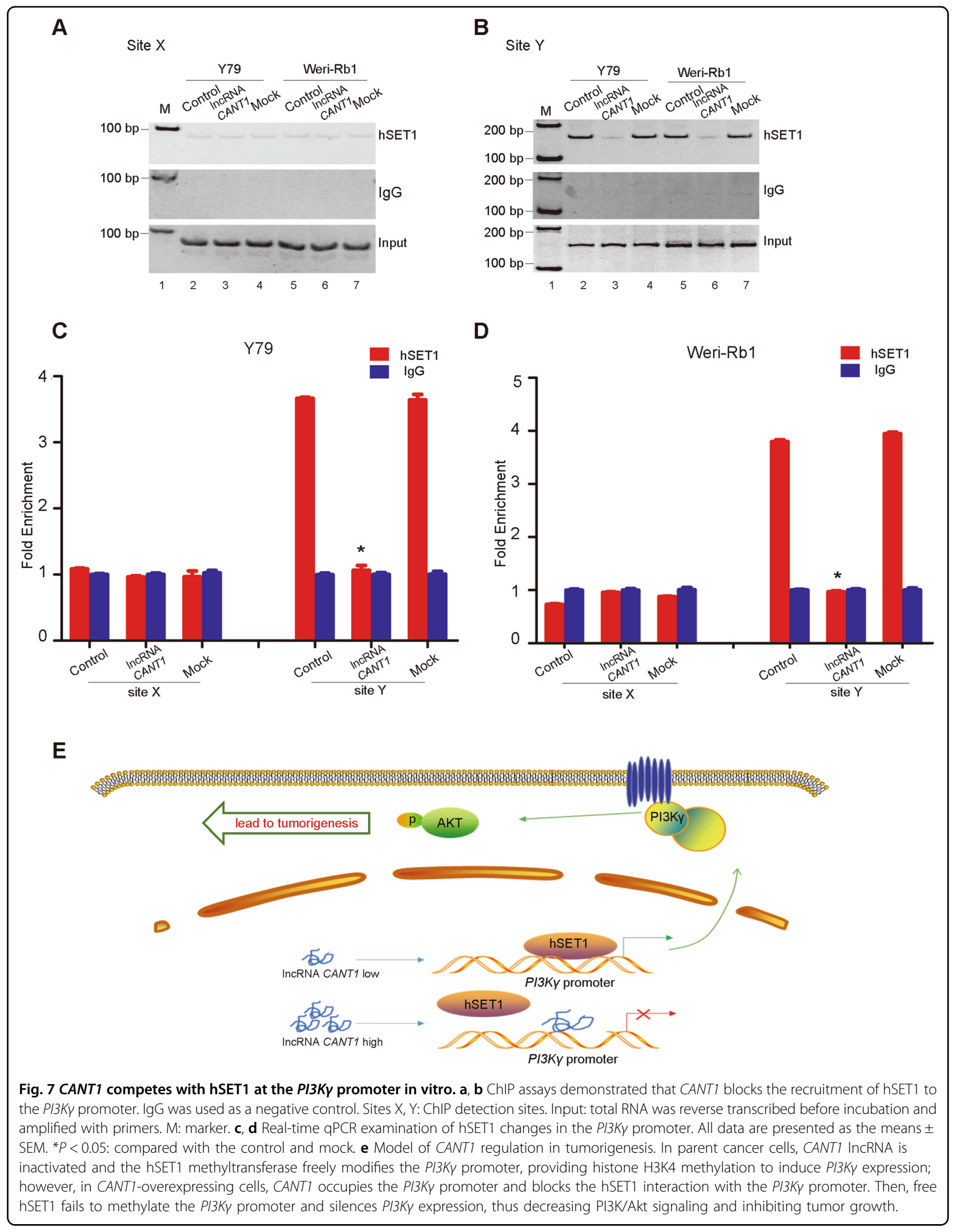


It has been shown that chromosome 6p22.3 is a tumor susceptibility locus that impacts tumor initiation and progression $^{30,31}$. Ensemble annotation predicted six CASC15 lncRNA isoforms, two of which (CASC15-003 and $C A S C 15-004)$ are widely expressed in neuroblastoma, predicting an improved clinical outcome with increased expression $^{32}$. Otherwise, the CASC15 isoform exerts oncogenic functions in the cutaneous melanoma progression $^{33}$. We previously reported that lncRNA CANT1 triggers a CANT1-JPX/FTX-XIST long noncoding pathway to suppress uveal melanoma progression ${ }^{15}$. Due to the etiology of eye neoplasms differing markedly from cutaneous melanomas and neuroblastomas, it is not surprising that the CANT1 isoform exists in RB and acts as a tumor suppressor that affects the characteristics of RB.

Studies have shown that class 1 phosphoinositide 3kinases(PI3Ks), consisting of $P I 3 K \alpha, P I 3 K \beta, P I 3 K \delta$, and $P I 3 K \gamma$, are a family of dual-specificity lipid and protein kinases that phosphorylate the inositol ring of phosphoinositides and then activate Akt, a serine/threonine kinase that directly phosphorylates a wide variety of targets participating in cell growth and survival ${ }^{34,35}$. PI3KY is a gene that plays different roles in various human malignancies. $P I 3 K \gamma$ is frequently deleted in myeloid malignancies and is evaluated as a candidate myeloid tumor suppressor gene ${ }^{36}$. However, in T-cell acute lymphoblastic leukemia, $P I 3 K \gamma$ can alone support leukemogenesis in the absence of PTEN phosphatase tumor suppressor function and serves as a nonclassical oncogene ${ }^{37}$. Others have reported that PI3K $\gamma$ may represent a suitable molecular target for therapeutic intervention in Kaposi's sarcoma and claudin-low breast cancer ${ }^{38-40}$. Study has shown that down-regulation of $P I 3 K \gamma$ expression and hypermethylation at $\mathrm{CpG}$ sites of the promoter regions were also detected in primary colon cancers ${ }^{41}$. It is reasonable for us to explore the methylation status of $\mathrm{PI} 3 \mathrm{KY}$ promoter region. In our study, we examined histone H3K4me3, H3K9me3 and H3K27me3 levels after lncRNA CANT1 overexpression. We found that histone H3K4me3 level was significantly changed after lncRNA CANT1 overexpression in this locus. Constitutive activation of PI3K/Akt signaling contributes to human neoplasias including $\mathrm{RB}^{42}$. In our study, CANT1 serves as a tumor suppressive lncRNA by modulating its downstream targets. By KEGG analysis, there are several signaling pathways predicted to be regulated by CANT1 (Fig. 3b). CANT1 inhibits RB progression depending in part on PI3K/Akt signaling attenuation, in which $P I 3 K \gamma$ is a key regulatory element.

It has been reported that the functional mechanisms of lncRNAs are diverse; here, we only considered lncRNA transcriptional regulation at the chromatin level because CANT1 was mainly localized in the nucleus. The activities of lncRNAs can affect neighboring intrachromosomal genes in cis or target genes on different chromosomes in trans. LncRNAs can regulate distant genes by serving as a scaffold for the assembly of multiple regulatory molecules at a single locus, or can also modulate chromatin structures by recruiting chromatin-modifying enzymes, resulting in expression or repression of a large number of genes $^{3,13,28}$. LncRNA NBAT1 (also called CASC14), the expression of which is decreased in neuroblastoma, functionally interacts with PRC2 member EZH2 and controls the expression of target genes via the loss of H3K27me3 from their promoter regions, resulting in neuroblastoma development ${ }^{43}$. However, IncRNAs can also serve as insulators to block regulatory factors from binding to DNA elements such as promoters involved in transcription. We previously reported that linc-ROR may function as a decoy oncoRNA that frees the histone methyltransferase G9A from binding to its target gene, promoting tumorigenesis ${ }^{13}$. In this report, we show that CANT1 is silenced in retinoblastoma and thus hSET1 methyltransferase is recruited to the $P I 3 K \gamma$ promoter, promoting its $\mathrm{H} 3 \mathrm{~K} 4$ trimethylation and activating $\mathrm{PI} 3 \mathrm{~K} \gamma$ expression. When CANT1 was overexpressed in RB cells, it occupied the $P I 3 K \gamma$ promoter and blocked hSET1 methyltransferase; consequently, H3K4me3 was lost from PI3K $\gamma$ promoter region.

It should be noted that RB is the most common intraocular tumor in childhood and the genetic basis of its occurrence and progression has been researched for decades. The classical hypothesis is that biallelic loss of the $R B 1$ gene results in the defective formation of the RB protein and triggers tumor initiation ${ }^{16}$. However, the mechanisms behind this rapid evolution of the tumor go far beyond RB1 inactivation. Further genetic or epigenetic alterations, such as $M Y C N$ amplification, inactivating mutations of $B C L-6$ co-repressor $(B C O R)$, the aberrant expression of $S Y K$, DNA copy number gains of KIF14 and noncoding RNAs, likely contribute to the malignant transformation $^{14,16,18,19,21,44}$. In addition, we previously reported for the first time that lncRNA GAU1 is a novel oncoRNA that promotes RB tumorigenesis ${ }^{14}$. In this study, through the genomic analysis of our previous profiling data, we identified that lncRNA CANT1 expression is markedly downregulated in $\mathrm{RB}$ tissues compared to that in normal tissues. Low expression levels of CANT1 correlated with some clinicopathological factors, such as tumor growth rate and increased tumor size, suggesting that $C A N T 1$ might be a potential therapeutic target and prognostic indicator of $\mathrm{RB}$.

In aggregate, our data suggest a novel mechanism in which lncRNA CANT1 serves as a tumor suppressor and outline a new pattern of histone modification in RB tumorigenesis. It is possible that CANT1 may block target gene expression by binding to DNA elements. Understanding the various roles of lncRNAs in tumor progression enables us to better explain the disease phenotype, improve the treatment regimens and provide reliable lncRNA-based prognostic markers. 


\section{Acknowledgements}

This work was supported by the National Natural Science Foundation of China (81772875, 81770961, and U1932135), and the Science and Technology Commission of Shanghai (17DZ2260100 and 19JC1410200).

\section{Conflict of interest}

The authors declare that they have no conflict of interest.

\section{Publisher's note}

Springer Nature remains neutral with regard to jurisdictional claims in published maps and institutional affiliations.

Supplementary Information accompanies this paper at (https://doi.org/ 10.1038/s41419-020-2524-y).

Received: 7 January 2020 Revised: 12 April 2020 Accepted: 14 April 2020 Published online: 04 May 2020

\section{References}

1. Guttman, M., Russell, P., Ingolia, N. T., Weissman, J. S. \& Lander, E. S. Ribosome profiling provides evidence that large noncoding RNAs do not encode proteins. Cell 154, 240-251 (2013).

2. Kay, G. F. et al. Expression of Xist during mouse development suggests a role in the initiation of X chromosome inactivation. Cell 72, 171-182 (1993).

3. Wang, K. C. et al. A long noncoding RNA maintains active chromatin to coordinate homeotic gene expression. Nature 472, 120-124 (2011).

4. Quinn, J. J. \& Chang, H. Y. Unique features of long non-coding RNA biogenesis and function. Nat. Rev. Genet. 17, 47-62 (2016).

5. Brown, C. J. et al. The human XIST gene: analysis of a $17 \mathrm{~kb}$ inactive $\mathrm{X}$-specific RNA that contains conserved repeats and is highly localized within the nucleus. Cell 71, 527-542 (1992).

6. Clemson, C. M., McNeil, J. A., Willard, H. F. \& Lawrence, J. B. XIST RNA paints the inactive $X$ chromosome at interphase: evidence for a novel RNA involved in nuclear/chromosome structure. J. Cell Biol. 132, 259-275 (1996).

7. Loewer, S. et al. Large intergenic non-coding RNA-RoR modulates reprogramming of human induced pluripotent stem cells. Nat. Genet. 42 1113-1117 (2010)

8. Lee, $\mathrm{S}$. et al. Noncoding RNA NORAD regulates genomic stability by sequestering PUMILIO proteins. Cell 164, 69-80 (2016).

9. Munschauer, $M$. et al. The NORAD IncRNA assembles a topoisomerase complex critical for genome stability. Nature 561, 132-136 (2018).

10. Faghihi, M. A. et al. Expression of a noncoding RNA is elevated in Alzheimer's disease and drives rapid feed-forward regulation of beta-secretase. Nat. Med. 14, $723-730$ (2008).

11. Vausort, M., Wagner, D. R. \& Devaux, Y. Long noncoding RNAs in patients with acute myocardial infarction. Circ. Res. 115, 668-677 (2014).

12. Yan, B. et al. IncRNA-MIAT regulates microvascular dysfunction by functioning as a competing endogenous RNA. Circ. Res. 116, 1143-1156 (2015).

13. Fan, J. et al. Long non-coding RNA ROR decoys gene-specific histone methylation to promote tumorigenesis. Genome Biol. 16, 139 (2015).

14. Chai, P. et al. Dynamic chromosomal tuning of a novel GAU1 Incing driver at chr12p13.32 accelerates tumorigenesis. Nucleic Acids Res. 46, 6041-6056 (2018).

15. Xing, Y. et al. CANT1 IncRNA triggers efficient therapeutic efficacy by correcting aberrant Incing cascade in malignant uveal melanoma. Mol. Ther. 25, 1209-1221 (2017)

16. Dimaras, H. et al. Retinoblastoma. Nat. Rev. Dis. Primers 1, 15021 (2015).

17. Dyson, N. J. RB1: a prototype tumor suppressor and an enigma. Genes Dev. $\mathbf{3 0}$ 1492-1502 (2016)

18. Benavente, C. A. \& Dyer, M. A. Genetics and epigenetics of human retinoblastoma. Annu. Rev. Pathol. 10, 547-562 (2015).

19. Felsher, D. W. Role of MYCN in retinoblastoma. Lancet Oncol. 14, 270-271 (2013).
20. Wu, N. et al. A mouse model of MYCN-driven retinoblastoma reveals MYCN-independent tumor reemergence. J. Clin. Invest. 127, 888-898 (2017).

21. Zhang, J. et al. A novel retinoblastoma therapy from genomic and epigenetic analyses. Nature 481, 329-334 (2012).

22. Dunn, K. C., Aotaki-Keen, A. E., Putkey, F. R. \& Hjelmeland, L. M. ARPE-19, a human retinal pigment epithelial cell line with differentiated properties. Exp. Eye Res. 62, 155-169 (1996).

23. Dunn, K. C. et al. Use of the ARPE-19 cell line as a model of RPE polarity: basolateral secretion of FGF5. Invest. Ophthalmol. Vis. Sci. 39, 2744-2749 (1998).

24. McFall, R. C., Sery, T. W. \& Makadon, M. Characterization of a new continuous cell line derived from a human retinoblastoma. Cancer Res. 37, 1003-1010 (1977).

25. McFall, R. C., Nagy, R. M., Nagle, B. T. \& McGreevy, L. M. Scanning electron microscopic observation of two retinoblastoma cell lines. Cancer Res. 38, 2827-2835 (1978).

26. $\mathrm{Xu}, \mathrm{H}$. et al. Characteristics of an established retinoblastoma cell line $\mathrm{HXO}$ Rb44. Yan Ke Xue Bao 11, 16-21 (1995).

27. lyer, M. K. et al. The landscape of long noncoding RNAs in the human transcriptome. Nat. Genet. 47, 199-208 (2015).

28. Tsai, M. C. et al. Long noncoding RNA as modular scaffold of histone modification complexes. Science 329, 689-693 (2010).

29. Sun, T. T. et al. LncRNA GClnc1 promotes gastric carcinogenesis and may act as a modular scaffold of WDR5 and KAT2A complexes to specify the histone modification pattern. Cancer Discov. 6, 784-801 (2016).

30. Maris, J. M. et al. Chromosome $6 \mathrm{p} 22$ locus associated with clinically aggressive neuroblastoma. N. Engl. J. Med. 358, 2585-2593 (2008).

31. Russell, M. R. et al. CASC15-S is a tumor suppressor IncRNA at the $6 \mathrm{p} 22$ neuroblastoma susceptibility locus. Cancer Res. 75, 3155-3166 (2015).

32. Mondal, T. et al. Sense-antisense IncRNA pair encoded by locus $6 \mathrm{p} 22.3$ determines neuroblastoma susceptibility via the USP36-CHD7-SOX9 regulatory axis. Cancer Cell 33, 417-434.e7 (2018).

33. Lessard, L. et al. The CASC15 long intergenic noncoding RNA locus is involved in melanoma progression and phenotype switching. J. Invest. Dermatol. 135 2464-2474 (2015).

34. Vanhaesebroeck, B. et al. Synthesis and function of 3-phosphorylated inositol lipids. Annu. Rev. Biochem. 70, 535-602 (2001).

35. Rommel, C., Camps, M. \& Ji, H. PI3K delta and PI3K gamma: partners in crime in inflammation in rheumatoid arthritis and beyond? Nat. Rev. Immunol. 7 191-201 (2007).

36. Kratz, C.P. et al. Genomic structure of the PIK3CG gene on chromosome band $7 q 22$ and evaluation as a candidate myeloid tumor suppressor. Blood 99 372-374 (2002)

37. Subramaniam, P. S. et al. Targeting nonclassical oncogenes for therapy in TALL. Cancer Cell 21, 459-472 (2012).

38. Brazzatti, J. A. et al. Differential roles for the p101 and p84 regulatory subunits of PI3Kgamma in tumor growth and metastasis. Oncogene 31, 2350-2361 (2012).

39. Martin, D. et al. PI3Kgamma mediates Kaposi's sarcoma-associated herpesvirus vGPCR-induced sarcomagenesis. Cancer Cell 19, 805-813 (2011).

40. Zhang, S. et al. Manic fringe promotes a claudin-low breast cancer phenotype through notch-mediated PIK3CG induction. Cancer Res. 75 1936-1943 (2015)

41. Semba, S. et al. Down-regulation of PIK3CG, a catalytic subunit of phosphatidylinositol 3-OH kinase, by $\mathrm{CpG}$ hypermethylation in human colorectal carcinoma. Clin. Cancer Res. 8, 3824-3831 (2002).

42. Xie, $\mathrm{C}$. et al. Co-deleting Pten with $\mathrm{Rb}$ in retinal progenitor cells in mice results in fully penetrant bilateral retinoblastomas. Mol. Cancer 14, 93 (2015).

43. Pandey, G. K. et al. The risk-associated long noncoding RNA NBAT-1 controls neuroblastoma progression by regulating cell proliferation and neuronal differentiation. Cancer Cell 26, 722-737 (2014).

44. De La Rosa-Velazquez, I. A., Rincon-Arano, H., Benitez-Bribiesca, L. \& RecillasTarga, F. Epigenetic regulation of the human retinoblastoma tumor suppressor gene promoter by CTCF. Cancer Res. 67, 2577-2585 (2007). 